\title{
Do lugar à rede e da rede ao lugar: as estratégias de apropriação do espaço em Itaboraí (RJ) diante das novas lógicas produtivas
}

From the place to the network and from the network to the place: the strategies of appropriation of space in Itaboraí (RJ) and the new logics of production Du lieu au réseau et du réseau au lieu : les stratégies d'appropriation de l'espace à l'Itaboraí (RJ) face aux nouvelles logiques productives

\section{Leandro Gondim Monteiro}

\section{OpenEdition}

Edição electrónica

URL: http://journals.openedition.org/espacoeconomia/125

DOI: 10.4000/espacoeconomia.125

ISSN: 2317-7837

Editora

Núcleo de Pesquisa Espaço \& Economia

Refêrencia eletrónica

Leandro Gondim Monteiro, « Do lugar à rede e da rede ao lugar: as estratégias de apropriação do espaço em Itaboraí (RJ) diante das novas lógicas produtivas », Espaço e Economia [Online], 1 | 2012, posto online no dia 09 março 2013, consultado o 15 novembro 2019. URL : http://

journals.openedition.org/espacoeconomia/125 ; DOI : 10.4000/espacoeconomia.125

Este documento foi criado de forma automática no dia 15 novembro 2019.

(C) NUPEE 


\section{Do lugar à rede e da rede ao lugar: as estratégias de apropriação do espaço em Itaboraí (RJ) diante das novas lógicas produtivas}

From the place to the network and from the network to the place: the strategies

of appropriation of space in Itaboraí (RJ) and the new logics of production

Du lieu au réseau et du réseau au lieu : les stratégies d'appropriation de l'espace

à l'Itaboraí (RJ) face aux nouvelles logiques productives

Leandro Gondim Monteiro

\section{Introdução}

1 A produção deste trabalho tem por objetivo demonstrar a importância de se compreender que as técnicas não são apenas um dado percebido no território. Não se tratam as técnicas, de meras próteses ou elementos que compõem o espaço geográfico. Tal afirmação pode parecer óbvia àqueles que lidam com as discussões sobre tal tema no ambiente acadêmico, no entanto, a ciência deve obrigatoriamente servir à sociedade, não se retendo à discussão nos bastidores das universidades, que estão longe de serem acessíveis à grande maioria da população, pelo menos na realidade que conhecemos, ou seja, a realidade brasileira.

2 Pretendemos, neste artigo, debater sobre a necessidade de se levar o conhecimento acadêmico para fora dos muros das instituições de ensino, e, especialmente neste trabalho produzir o conhecimento para que se possa revelar a dimensão política que influencia e é ao mesmo tempo influenciada pelas técnicas, e assim discutir os impactos territoriais da futura instalação do complexo petroquímico da Petrobrás na região do Leste Metropolitano Fluminense. Tal evento revela uma das faces e tendências da globalização (SANTOS, 2001) que é a da internacionalização e flexibilização do capital 
no que tange à localização das bases produtivas. Acreditamos que a chegada da Petrobras ao Leste Metropolitano Fluminense coloca em evidência a importância do território, que expressa a delimitação espacial das relações de poder, e de seu uso para a compreensão das possibilidades de alcance do real desenvolvimento, conceito o qual iremos dar um maior enfoque no desenvolver deste artigo.

\section{Fatores que motivaram a produção deste artigo}

3 Desde o ano de 2004, quando foi anunciado que uma base produtiva da Petrobrás se instalaria em Itaboraí, e que o "Centro de Formação de Inteligência" seria o município de São Gonçalo, uma série de propagandas em outdoors trazem como idéia principal o fato de que a instalação da empresa petrolífera trará não só a Itaboraí e São Gonçalo, mas, ao conjunto maior da população localizada na região do Leste Metropolitano Fluminense, uma série de melhorias estruturais e também sociais, sobretudo no que tange à grande oferta de empregos e aos investimentos na área da educação. No entanto, São Gonçalo, por exemplo, é um dos municípios que possuem um dos maiores números de indústrias em seu território, o que não significa que uma parcela expressiva de sua população moradora seja beneficiada pela presença de tais indústrias. Muito pelo contrário, uma grande parte dos moradores de São Gonçalo sequer trabalha em seu município, tendo que se deslocarem para o Rio de Janeiro, ou, para Niterói em busca de oportunidades. Seria então a Petrobrás uma solução aos problemas de ordem social nos municípios do Leste Metropolitano? Colocamos alguns dados abaixo que parecem demonstrar que não é exatamente a indústria, e no caso em análise, a Petrobrás que irá solucionar os problemas gerados por anos de baixos investimentos no setor social destes municípios. 
Leste Metropolitano Fluminense

Municípios que integram o Leste Metropolitano Fluminense.

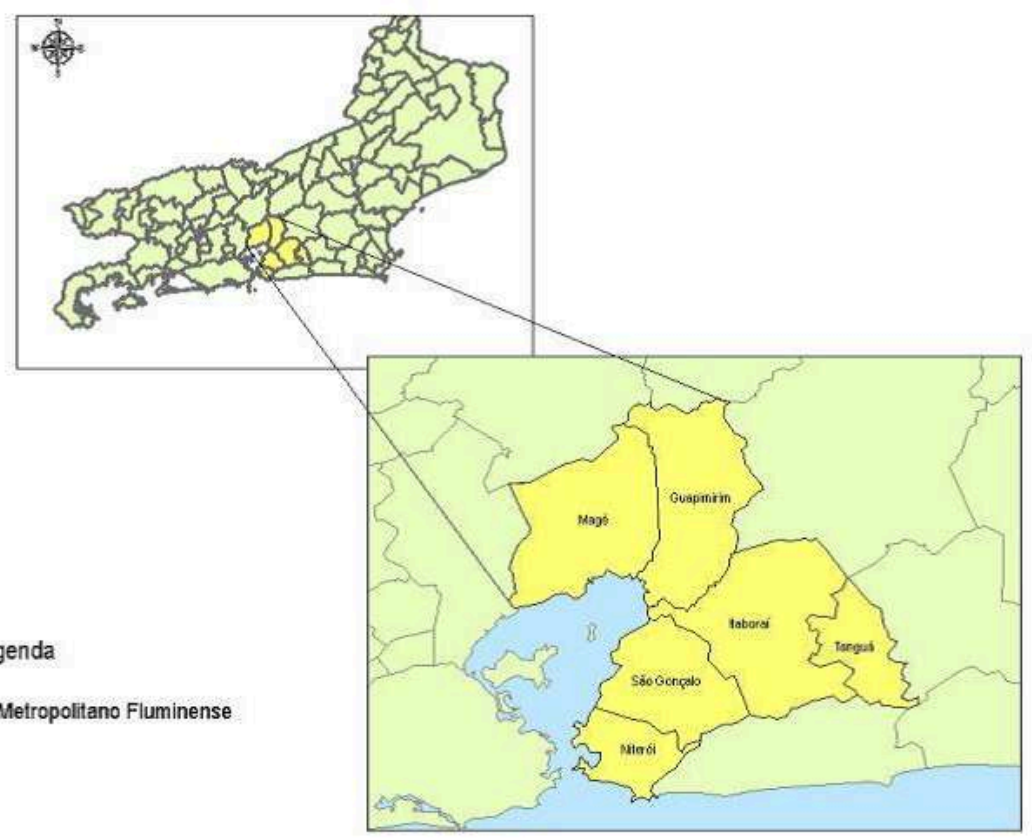

FONTE: IBGE

Quadro 1: Os seis maiores municípios em número de estabelecimentos industriais no Estado do Rio de Janeiro (2005)

\begin{tabular}{|l|l|}
\hline Rio de Janeiro & 11.871 \\
\hline Duque de Caxias & 1.639 \\
\hline Nova Friburgo & 1.525 \\
\hline Petrópolis & 1.289 \\
\hline São Gonçalo & 1.251 \\
\hline Niterói & 855 \\
\hline
\end{tabular}

FONTE: RAIS 
Tabela 1: Estimativa de famílias pobres no Leste Metropolitano Fluminense (2006)

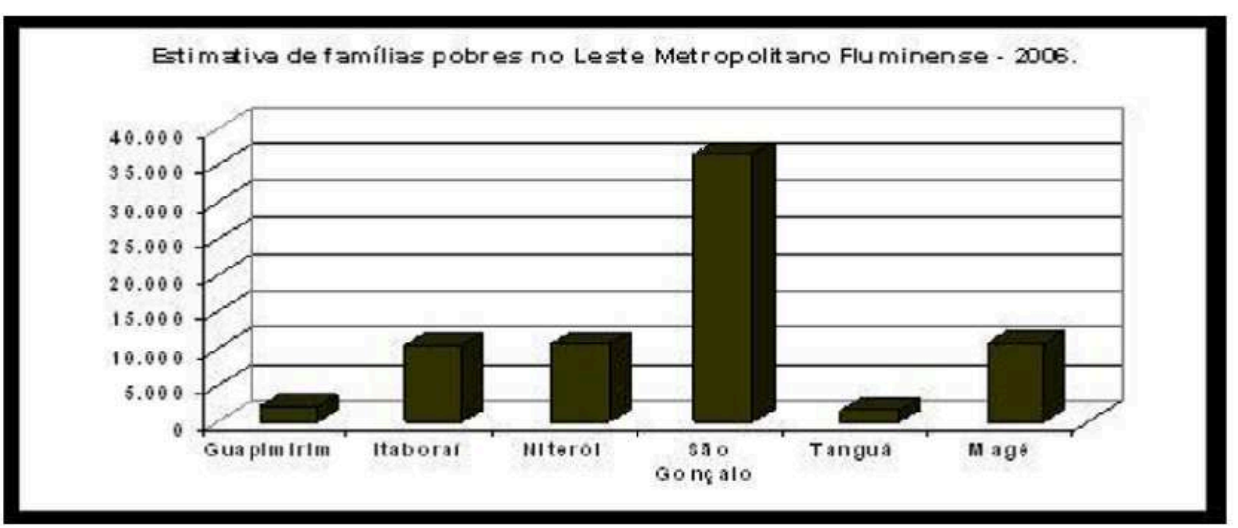

FONTE: MINISTÉRIO DO DESENVOLVIMENTO SOCIAL

4 Ao participar de audiências públicas como a da "Agenda 21" para o desenvolvimento dos municípios do COMPERJ, realizada no ano de 2006 no município de Itaboraí, o que pude observar era a veiculação da idéia de que a vinda da base produtiva de petróleo para aquele município significava um avanço tecnológico, que não só permite a Petrobrás fragmentar as fases de produção, beneficiamento e comercialização de seu principal produto, o petróleo, mas, que também permite a empresa trazer grandes benefícios não só para o Leste Fluminense, mas, à toda a economia do Estado do Rio de Janeiro.

5 Neste mesmo evento, que reuniu uma grande quantidade de associações de moradores, de representantes do poder político local, de munícipes e, é claro de representantes da própria empresa, o que se percebia era um ambiente de dúvidas e de discussões ásperas. Os moradores, em sua maioria, cobravam dos representantes da empresa a garantia de tais melhoras prometidas nas propagandas veiculadas em Itaboraí. Os representantes da Petrobrás, por sua vez, diziam que as melhorias não eram de responsabilidade da empresa somente, mas, da prefeitura local e de outras esferas governamentais. Os representantes da prefeitura em seus respectivos discursos se mostravam como os grandes benfeitores por terem conseguido trazer para Itaboraí a base produtiva da Petrobrás e que a partir da chegada da empresa eles se comprometeriam a exercer ações que traria ganhos para a empresa e principalmente para a população local.

6 É com base na experiência vivenciada no ano de 2006 na audiência pública é que retomo à idéia desenvolvida no primeiro parágrafo deste artigo. É preciso levar a discussão sobre o uso político das técnicas a um conjunto maior da sociedade, promovendo o que Boaventura de Souza Santos chamaria de dupla ruptura epistemológica (SANTOS, 1998).

7 Sem dúvidas, a instalação da base da Petrobrás na região do Leste Metropolitano Fluminense acaba por expressar a importância estratégica do território para as aspirações produtivas da empresa. É indubitável também que o uso político do anunciar do empreendimento produtivo, proferido pelos governantes dos municípios que serão e que já estão sendo impactados pelo complexo petroquímico, servirá ao propósito de dar ainda mais notoriedade eleitoral a estes governantes, o que poderá vir a contribuir para com uma possível permanência em cargos políticos e, quiçá, para o alcance de objetivos eleitoreiros maiores. Existe também a possibilidade de um conjunto maior da população gozar de benefícios oriundos do investimento em debate, mas, é neste momento que se 
faz importante atentar para a idéia de que o território possui importância estratégica, sendo possível à população local reivindicar maiores ganhos diante do interesse do capital produtivo e da própria esfera governamental. Prefeitos e governadores não são os detentores do território, mas, são representantes da sociedade local, que é de fato aquela que assume o papel de serem responsáveis em grande pela parte pela construção e organização do território por intermédio de suas respectivas ações.

Insistimos na tese de desvendar os interesses políticos contidos nas técnicas porque em muita das vezes as técnicas são esvaziadas de seu conteúdo político. Segundo Milton Santos:

"Esses objetos novos, que transportam o sistema das técnicas atuais, exigem discurso. Até ontem, eles nos podiam falar diretamente; hoje, nós os miramos, mas eles nada nos dizem, se não houver a possibilidade de uma tradução. Por isso, as cidades, mesmo as do interior, acolhem um grande número de tradutores, pessoas treinadas para ler sistemas técnicos e utilizar objetos técnicos". (SANTOS, 1994, p. 56)

9 Esta situação se agrava quando consideramos a lógica da velocidade, que muita das vezes nos impede de construir uma reflexão um pouco mais aprofundada da realidade que nos cerca. Ao morador de Itaboraí, por exemplo, a presença da base produtiva da Petrobrás poderá ser visto como algo que trará uma melhoria para o município, sem que ele mesmo, o morador sinta de fato estes benefícios. A isto se deve o poder da propaganda que prega um discurso descolado da realidade. Esta dimensão ideológica, de que a presença de uma estrutura produtiva irá remeter a um avanço tecnológico, que por sua vez levará ao alcance do desenvolvimento, muita das vezes passa por despercebida por aqueles a quem Milton Santos denomina como sendo os "homens rápidos", ou seja, aqueles que de fato não vivenciam, ou são impossibilitados de vivenciar e experenciar de forma plena a realidade que os cerca. Segundo Santos:

“Creio, porém, que na cidade, na grande cidade atual, tudo se dá ao contrário. A força é dos "lentos" e não dos que detêm a velocidade elogiada por um Virilio em delírio na esteira de um Valéry sonhador. Quem, na cidade, tem mobilidade - e pode percorrê-la e esquadrinhá-la - acaba por ver pouco da Cidade e do Mundo. Sua comunhão com as imagens, frequentemente prefabricadas, é a sua perdição. Seu conforto, que não desejam perder, vem exatamente do convívio com essas imagens. Os homens "lentos", por seu turno, para quem essas imagens são miragens, não podem, por muito tempo, estar em fase com esse imaginário perverso e acabam descobrindo as fabulações. A lentidão dos corpos contrastaria então com a celeridade dos espíritos?" (idem, p.41).

\section{Um novo paradigma produtivo em curso}

10 Quando se afirma que a indústria é o fator norteador para o desenvolvimento é preciso levar em consideração o atual estágio das técnicas (SANTOS, 2004). O advento do atual período técnico interfere na dinâmica produtiva contemporânea, principalmente, quando se trata da questão do número de postos de trabalho que a atual indústria é capaz de gerar. Em tempos atuais o que se verifica é uma indústria que se caracteriza cada vez mais pela larga utilização de tecnologia em sua base produtiva, recrutando um número cada vez menor de trabalhadores nesta mesma base.

11 Se até a década de 1970 o capitalismo industrial encontrava-se no auge do ciclo de produção e acumulação, possibilitando o emprego de um número expressivo de trabalhadores na base produtiva -- o que era condição para uma lógica de produção e 
consumo em massa -- os anos seguintes irão expressar amplas modificações na lógica produtiva das bases industriais. As chances de uma nova recessão econômica que se origina em dois eventos ligados às crises do petróleo em 1973 e 1979, levam o grande capital a inovar suas formas de acumulação e reprodução. Os esforços capitalistas no sentido de se evitar uma nova "crise de 1929" irão dar início a uma gradual transição do sistema fordista de produção para o sistema de produção e acumulação flexível.

Quando se estabelece a idéia de que a indústria é o mecanismo que promove o desenvolvimento local (ou que em muito contribui para o alcance do desenvolvimento) devemos considerar que estamos diante de um período que denominamos de terceira revolução industrial período este em que se percebe claramente uma série de modificações na relação entre a base produtiva e o território onde tal se localiza. Ao observar, por exemplo, a ação das indústrias multinacionais no território fluminense (como nos casos da instalação da Volkswagen e da Peugeot no Médio Vale do Paraíba Fluminense), percebe-se que a base produtiva não mais provoca a mesma sinergia econômica como no período em que o modelo fordista de produção era predominante. Utilizando-nos da periodização técnica proposta por Santos, poderíamos afirmar que estamos diante do meio técnico-científico-informacional. Neste período, ciência e técnica se complementam permitindo amplo avanço tecnológico. Dentre os setores que mais fazem expressar este avanço estão os setores de transporte e comunicação. Segundo Santos:

"Essa união entre técnica e ciência vai dar-se sob a égide do mercado. E o mercado, graças exatamente à ciência e a técnica torna-se um mercado global (...) Neste período, os objetos técnicos tendem a ser ao mesmo tempo técnicos e informacionais, já que, graças a extrema intencionalidade de sua produção e de sua localização, eles já surgem da informação; e, na verdade a energia principal de seu funcionamento é também a informação. Já hoje, quando nos referimos às manifestações geográficas decorrentes dos novos progressos, não é mais de meio técnico que se trata. Estamos diante da produção de algo novo, a que estamos chamando de meio técnico-científico-informacional" (idem, p. 238).

13 É essencial destacar a importância desta união entre técnica e ciência, e, que esta união, vem a servir fundamentalmente ao grande capital. A atual indústria utiliza desta tecnologia principalmente para ganhar mobilidade espacial e flexibilidade produtiva.

14 Até se chegar a este grau de mobilidade e flexibilidade, a indústria, principalmente no que tange aos seus sistemas produtivos, passou por um alto grau de modificações. Diríamos que, a primeira modificação no sistema produtivo industrial, está relacionada, ao desenvolvimento dos meios de transporte onde as locomotivas, que já representavam uma mudança significativa em termos de transporte, foram sendo substituídas por meios de transporte cada vez mais rápidos, permitindo a diminuição do tempo necessário ao deslocamento de mercadorias em grande quantidade de um ponto ao outro.

15 Em tempos atuais, a indústria dotada de possibilidades de ordem técnica, apresenta alto grau de flexibilidade tanto em relação às formas de produção quanto nas relações de trabalho, apresentando intensas modificações em relação às indústrias pioneiras. Graças ao avanço da informática a atual indústria encontra a possibilidade de se fragmentar territorialmente, com a separação entre os centros gestores e as bases de produção, tornando-se flexível. Neste sentido, as inovações tecnológicas não se restringem aos meios de transporte e comunicação, mas, atingem também, as bases de produção industrial e conseqüentemente os fatores que irão influenciar o processo de 
produção do espaço. Cada vez mais a atual indústria incorpora tecnologia nas fases de produção, substituindo a força de trabalho humana pela máquina. Neste ambiente de avanço tecnológico, os fatores locacionais tradicionais são substituídos pelas densidades técnicas e informacionais presentes nos lugares.

Esta incorporação de tecnologia nas fases da produção industrial permite um controle do Capital sobre o trabalhador sob duas vertentes: a primeira é que a máquina dita o ritmo de produção do trabalhador, sendo a máquina, um mecanismo regulador no processo de produção; a segunda é o fato de que a substituição do homem pela máquina aumenta ainda mais o número de trabalhadores desempregados. A ameaça do desemprego a que está submetido o trabalhador permite ao Capital, flexibilizar as leis trabalhistas através de contratos de trabalho flexíveis, ou, temporários. A ameaça iminente do desemprego submete o trabalhador a contratos que só beneficiam ao empregador.

Em se tratando da relação indústria e o território, esta se modifica totalmente diante da possibilidade da mobilidade espacial gerada pelas inovações tecnológicas nos sistemas de transporte e comunicação. Se antes a indústria investia em um determinado local, mesmo que este investimento atendesse às necessidades da própria indústria, hoje ela não mais se ocupa desta função. Em tempos atuais é o Estado o grande responsável pela criação de densidades técnicas no território que irão atrair os investimentos produtivos.

18 A seletividade espacial torna-se trunfo da nova indústria na busca do lucro ampliado. Neste sentido advém a guerra dos lugares, fruto da ambição dos administradores públicos, ansiosos pela localização industrial em seu município, ou, estado. Geralmente estes administradores apelam para justificativa de que a instalação da indústria em um determinado lugar é propicia à criação de oportunidades de trabalho, como vem ocorrendo no Leste Metropolitano Fluminense. Porém, é mais do que sabido que a atual indústria não é capaz de gerar empregos como no período fordista.

A oferta de empregos é abalada pelo desenvolvimento tecnológico, ou, melhor dizendo, pela forma a qual as novas tecnologias são apropriadas por grupos dominantes dentro das sociedades de uma forma geral. A produção não mais possibilita o estoque, uma vez que se produz de acordo com a demanda do mercado consumidor. O estoque de mercadorias no atual contexto significa capital imobilizado, algo extremamente prejudicial na perspectiva do investimento e do alcance do lucro ampliado. Ao invés de imobilizar capital, é mais vantajoso à burguesia, utilizar deste capital para diversificar as formas de se investir e de se obter o lucro de forma ampliada. Uma diminuição então do ritmo de produção, diminui a necessidade de se empregar um número expressivo de trabalhadores. Neste momento o leitor pode sugerir o seguinte questionamento: Não seria a Petrobrás uma indústria de base, que foge à flexibilidade de uma empresa "leve"? A resposta seria sim, no entanto, os governantes discursam que a Petrobrás por sua vez também irá atrair outras indústrias, que não necessariamente serão indústrias de base.

Infelizmente, em muita das vezes, a moderna indústria mantém um enorme distanciamento em relação ao território onde esta se encontra. A empresa, nacional ou multinacional, apropria-se de uma porção do espaço somente visando lucrar de forma ampliada. Este fato, porém, não representa nenhuma novidade. Enfocamos neste sentido, a importância de compreender a realidade a partir da analise do papel das técnicas e sua função política e porque não dizer econômica no território. 


\section{A indústria e o real desenvolvimento}

21 A idéia de se valorizar o conceito de real desenvolvimento, como foi dito no primeiro parágrafo deste artigo é motivado pelo fato de que muitas vezes o desenvolvimento é interpretado somente como o resultado do crescimento econômico alcançado num determinado contexto. Porém, o desenvolvimento de fato só é alcançado quando a sociedade é contemplada também por este crescimento econômico, principalmente, quando este se converte em investimentos no setor social. o desenvolvimento, na verdade, relaciona-se à conquista da cidadania plena, que só é possível diante de grandes melhoras nas estruturas que possam conferir aos indivíduos o acesso pleno ao conhecimento não só sobre seus direitos, mas, aos deveres, e, é claro, o aceso às condições de se cumprir tais deveres e alcançar tais direitos.

Para além do fato da indústria se encontrar em uma nova fase técnica, empregando um número cada vez menor de trabalhadores, podemos afirmar que nunca foi o principal objetivo e muito menos dever da indústria ser o fator promovedor do desenvolvimento. É objetivo da indústria, inovar cada vez mais os seus métodos produtivos visando obter resultados expressivos na busca pelo lucro em escala ampliada.

É importante esclarecer que a função de garantir as condições que permitam o alcance do real desenvolvimento pertence ao Estado. O Estado, por sua vez, mostra-se cada vez menos cumpridor de suas obrigações sociais, e esta tendência se intensifica no contexto do neoliberalismo, onde o Estado revela-se um agente fomentador das condições que visam a permitir o desenvolvimento do sistema capitalista de produção, e não o desenvolvimento em seu sentido pleno.

No Leste Fluminense, a ausência do poder público na garantia de condições básicas à população como saúde, educação e saneamento básico provoca um sério questionamento à estrutura política municipal. 0 que se detecta nestes municípios é a velha estrutura política que tem como base às "tradicionais" práticas assistencialistas. As condições históricas de degradação social sofridas pela população mais pobre são utilizadas como mecanismos de permanência no poder por parte de políticos mal intencionados, que se utilizam, cada vez mais, do "discurso das carências".

\section{Nova indústria e velha estrutura política: um entrave para o real desenvolvimento}

25 A utilização do conceito de real desenvolvimento é uma humilde provocação feita pelo autor deste artigo no debate sobre a visão economicista que em muita das vezes influência a concepção do conceito de desenvolvimento. É comum notarmos a utilização do conceito de desenvolvimento para caracterizar o crescimento econômico de um determinado contexto, como já dissemos anteriormente, ou, para enfocar o grau de inovação da tecnologia de uma dada realidade. Ora, o desenvolvimento não é somente o crescimento econômico e muito menos o simples desenvolvimento tecnológico. Se colocado apenas em sua dimensão econômica e tecnológica o desenvolvimento já foi há muito tempo alcançado em muitas realidades. O desenvolvimento chega a ser confundido com o desenvolvimento do capitalismo, modode-produção que, pelo menos até o presente momento, se distancia da função de trazer 
benefícios à sociedade como um todo. A idéia de que os avanços tecnológicos por si só representem uma realidade melhor aos indivíduos faz parte daquilo que Milton Santos chama de fábula da globalização. Segundo Maria da Conceição Tavares em Destruição Não Criadora, "este mundo globalizado, visto como fábula, erige como verdade um certo número de fantasias, cuja repetição, entretanto, acaba por se tornar uma base aparentemente sólida de sua interpretação" (TAVARES apud SANTOS, 2001, pp. 18-19).

A máquina ideológica que sustenta as ações preponderantes da atualidade é feita de peças que se alimentam mutuamente e põem em movimento os elementos essenciais à continuidade do sistema. Damos aqui alguns exemplos. Fala-se, por exemplo, em aldeia global para fazer crer que a difusão instantânea de notícias realmente informa as pessoas. A partir desse mito e do encurtamento das distâncias - para aqueles que realmente podem viajar - também se difunde a noção de tempo e espaço contraídos. É como se o mundo se houvesse tornado, para todos, ao alcance da mão. Um mercado avassalador dito global é apresentado como capaz de homogeneizar o planeta quando, na verdade, as diferenças locais são aprofundadas. Há uma busca de uniformidade, ao serviço dos atores hegemônicos, mas o mundo se torna menos unido, tornando mais distante o sonho de uma cidadania verdadeiramente universal. Enquanto isso, o culto ao consumo é estimulado.

Entender que o uso político das técnicas pode resultar em ganhos ou perdas para o conjunto da população é fundamental para uma discussão sobre o próprio tipo de uso das técnicas. No debate sobre a instalação do COMPERJ é necessário e estratégico entender que a localização geográfica do Leste Metropolitano Fluminense é de grande importância para que ocorra a consolidação da cadeia produtiva de petróleo do estado do Rio de Janeiro.

Junto ao COMPERJ será também implantado próximo às áreas de influência da base produtiva, o arco rodoviário, que possibilitará não só a Petrobrás, mas, às outras empresas "off-shore" a fuga de vias de transportes já congestionadas. $\mathrm{O}$ arco rodoviário viabilizará o acesso ao porto de Itaguaí, consolidando desta forma o complexo petroquímico do Estado do Rio de Janeiro. Nos mapas abaixo podemos ter uma noção da área de influência do COMPERJ, assim como uma visão do arco rodoviário. 


\section{Área de influência do COMPERJ e Arco Rodoviário}
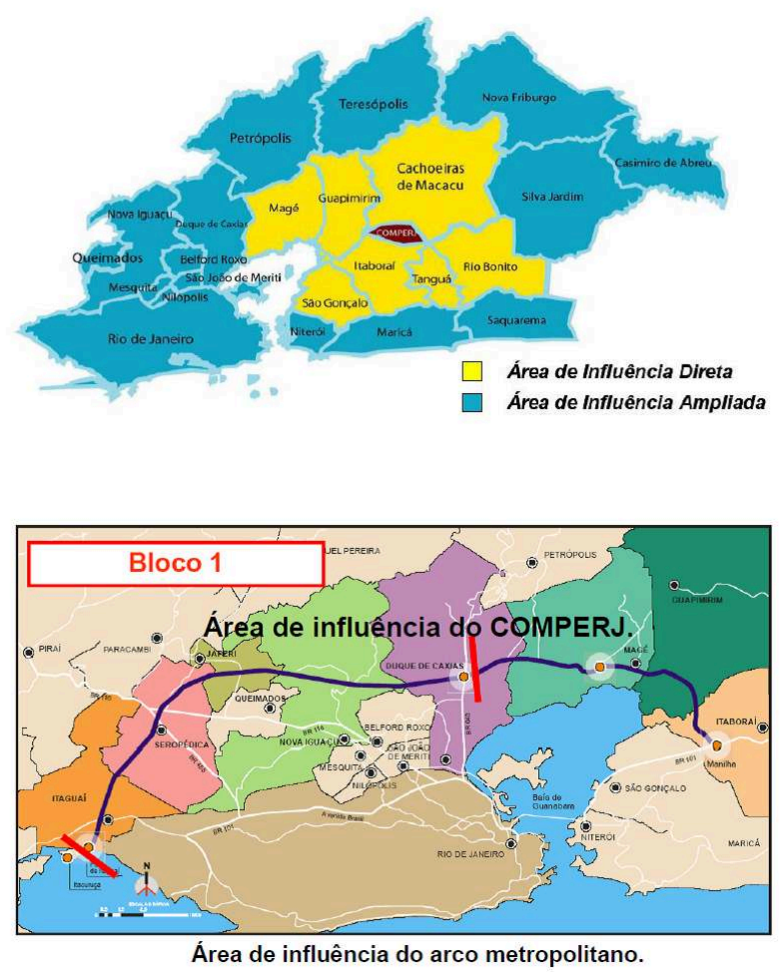

FONTE: HTTP://WWW.COMPERJ.COM.BR/

Com a opção pelo petróleo (uma opção política) como sendo a principal matriz energética a ser utilizada em nosso país, as ações da Petrobrás passam a atrair uma especial atenção por parte do governo brasileiro. Não podemos perder de vista, no entanto, que assim como qualquer outra empresa, o interesse da Petrobrás é de alcançar o lucro em larga escala. Se os investimentos produtivos não vierem a favorecer os verdadeiros detentores do território, ou seja, a população local, será a empresa e os dirigentes políticos dos municípios impactados os únicos a serem beneficiados pelos altos investimentos para a instalação da Petrobrás.

Aliás, a grande parte do capital que subsidia as ações da Petrobrás é de origem pública e, portanto, nada mais justo que as ações desta empresa possam em alguma medida auxiliar o alcance de melhorias para a população local.

31 Muito se costuma dizer que é a falta de planejamento (inclusive de planejamento urbano) que impede a conquista de ganhos para o território quando este se encontra prestes a receber um investimento produtivo. Humildemente discordamos de tal tese. Minimizar o Estado e dizer que este não planeja suas decisões e ações é no mínimo um erro. Talvez o que ocorra é o fato de que o planejamento do Estado brasileiro assim como as suas decisões e ações não venha de encontro com os interesses de um conjunto maior de nossa sociedade, o que leva à idéia de planejamento ineficaz ou de total ineficácia do que se entende por planejamento. Ora, o próprio planejamento é em si uma técnica, que quando investigada irá expressar uma intencionalidade política. Logo, o que se deseja é a revelação da intencionalidade política não só no uso da técnica, mas, também do processo de construção e implementação destas técnicas. 


\section{Conclusões}

32 Ao final deste artigo podemos afirmar que se mantida a velha estrutura política na região do Leste Metropolitano Fluminense, a vinda da Petrobrás em nada contribuirá para a melhoria das condições de vida da população local. Para que tal quadro seja revertido é necessária uma grande transformação na forma de gestão do território, principalmente, na perspectiva de uma maior proximidade entre o poder local e a população.

O real desenvolvimento no Leste Metropolitano Fluminense será um projeto impossível de ser concebido na atual conjuntura política, mesmo diante de avanços tecnológicos, que, como já fora discutido não são sinônimos de desenvolvimento. Concluímos com muitas dúvidas acerca dos impactos que serão gerados na região do Leste Metropolitano Fluminense e de como nós, cientistas sociais, podemos contribuir no sentido de propiciar a sociedade os instrumentos de luta contra uma realidade sistêmica perversa. 0 que podemos afirmar é que esta conclusão não encerra de forma alguma a discussão sobre tal tema, muito pelo contrário, é interesse do autor deste artigo investigar ainda mais o cenário de transformações na região do Leste Metropolitano Fluminense.

\section{BIBLIOGRAFIA}

OLIVEIRA, Floriano J. Godinho de. Mudanças no espaço metropolitano: novas centralidades e dinâmicas espaciais na metrópole fluminense. In: FREIRE, Désirée Guichard, OLIVEIRA, Floriano José Godinho de, SILVA, Catia Antonia da (orgs.). Metrópole: governo sociedade e território. Rio de Janeiro: DP\&A, 2006.

\section{. Reestruturação Produtiva e Regionalização da Economia no Território Fluminense. Tese}

(Doutorado em Geografia Humana). Departamento de Geografia da Faculdade de Filosofia, Letras e Ciências Humanas, Universidade de São Paulo, São Paulo, 2003.

SANTOS, Boaventura de Sousa. Introdução a uma ciência pós-moderna. Lisboa: Afrontamento, 1998.

SANTOS, Milton. A natureza do espaço - técnica e tempo, razão e emoção. São Paulo: Edusp, 2004.

- Por uma outra Globalização - do pensamento único à consciência universal. Rio de Janeiro: Record, 2003.

Técnica, espaço, tempo - Globalização e meio técnico-científico-informacional. São Paulo: Edusp, 1994.

\section{RESUMOS}

Este artigo versa sobre os impactos do crescimento econômico no município de Itaboraí (RJ), que receberá o maior investimento da história da Petrobras: o COMPERJ. Face à reestruturação 
produtiva, no plano metodológico é mister articular as escalas de análise para compreendermos o capitalismo contemporâneo.

This paper discusses the impacts of economic growth in Itaboraí (RJ), which receive the largest investment in the Petrobras' history, the COMPERJ. Granted the restructuring process, the methodological approach its necessary to articulate the scales of analysis to understand the contemporary capitalism.

Cet article porte sur les impacts de la croissance économique de la municipalité de Itaboraí (Rio de Janeiro), lieu du plus grand investissement de l'histoire de la Petrobras : le COMPERJ. Devant la reestructuration de la production, sur le plan méthodologique il faut articuler les échelles d'analyse pour comprendre le capitalisme contemporain.

ÍNDICE

Mots-clés: espace, territoire, développement, mondialisation, agents sociaux Keywords: space, territory, development, globalization, social agents

Palavras-chave: espaço, território, desenvolvimento, globalização, agentes sociais

\section{AUTOR}

\section{LEANDRO GONDIM MONTEIRO}

Mestrando do curso de Planejamento Urbano e Regional do IPPUR/UFRJ. Membro do Núcleo de Pesquisas Espaço e Economia (NUPEE). E-mail: leandrogondim@ig.com.br 